\title{
Design and Implementation of A Fuzzy Logic Based A Photovoltaic Peak Power Tracking Controller
}

\author{
Dr. Khalid K. Muhammed Marwan A. Abdulhameed \\ University of Mosul - College of Engineering - Electrical Department
}

\begin{abstract}
The output power induced in the photovoltaic (PV) cells is influenced by the intensity of the solar radiation, the temperature of the solar cells and the load connected to the solar panels. Therefore, to make PV cells keep giving maximum power under different operating conditions, a Maximum Power Point Tracking (MPPT) strategy is required. The Fuzzy logic controller (FLC) is one of most sufficient control strategies used for MPPT. FLC based on linguistic rules describing the operators control strategy is applied to control the step-up converter for MPPT. The proposed PV system design is evaluated and tested by computer simulations, using Matlab/Simulink facilities. Practical implementation is also included in this study. The fuzzy based MPPT algorithm is written in assembly language using the fuzzy logic instructions supported with the microcontroller HC12 MCU. Simulated and practical results are presented under different operating conditions in order to determine the tracker efficiency. The MPPT has been tested with three -, five- and seven-terms of linguistic variables for each input/output fuzzy label. The tracker efficiency is about $\mathbf{9 2 \%}$ using three fuzzy subsets with some fluctuation and about $95 \%$ using five fuzzy subsets with less fluctuation. By using seven fuzzy subsets, the tracker efficiency amounts to $99.9 \%$ and the system seems to be extremely stable with minimum fluctuation.
\end{abstract}

Keywords: Fuzzy Logic, Photovoltaic, MPPT

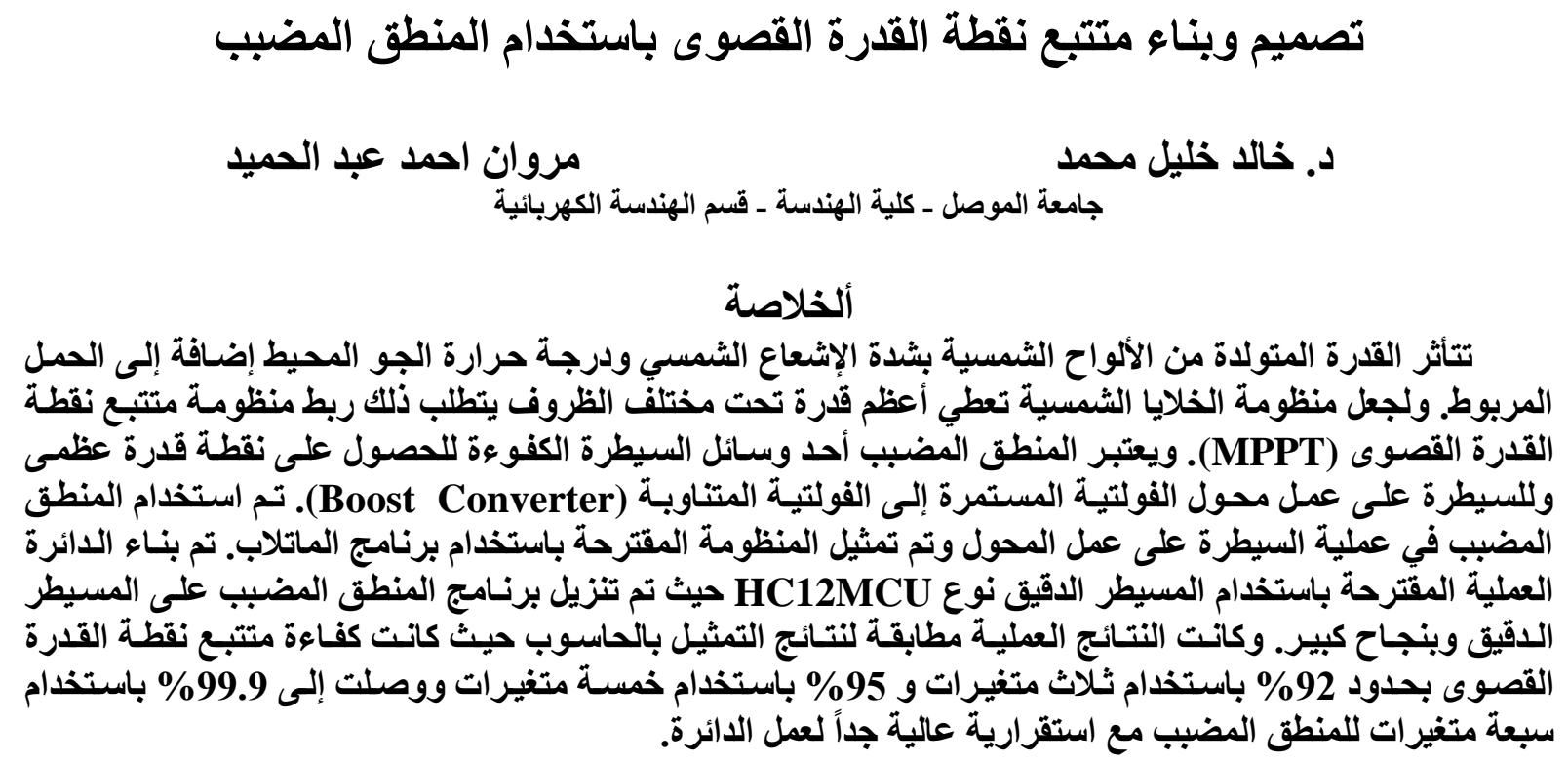

Received: 25 - 94 - 2011

Accepted: $24-10$ - 2011 


\subsection{Introduction:}

A PV array is by nature a nonlinear power source, which under constant uniform irradiance has a current-voltage $(I-V)$ and power-voltage $(P-V)$ characteristics as shown in Figure (1)[1]. There is a unique point on the curve, called the maximum power point (MPP) at which the array operates with maximum efficiency and produces maximum output power. This MPP varies with the solar intensity and temperature, shading conditions, and PV cells aging, so it is necessary to constantly track the MPP of the solar array. A switch-mode power converter, called the maximum power point tracker (MPPT), can be used to maintain the PV array's operating point at the MPP [2]. The MPPT can locate and track the MPP of the PV array in the $I-V$ characteristic, either through model calculations or by a search

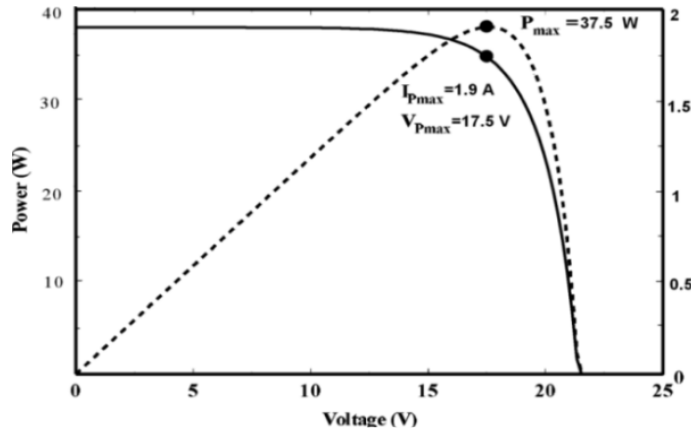

Figure (1): PV array $(I-V)$ and $(P-V)$ characteristics $[1]$ algorithm.

Different control strategies have been implemented for MPPT. The Fuzzy logic controller (FLC) is one of most sufficient control strategies used for MPPT. Simplicity and less intensive mathematical design requirements are the most important features of FLC. These features allow FLC to be easily implemented using inexpensive hardware technology. This had made digital FLC the most commercially successful implementation of fuzzy logic circuits [3].

\subsection{Solar Cell Characteristics:}

Solar cells have non-linear properties due to the semiconductor structure inside them [4]. An ideal solar cell can be represented by a current source connected in parallel with a rectifying diode, Figure (2) shows the equivalent circuit for solar cell. The corresponding I-V characteristic is described by the Shockley solar cell equation :

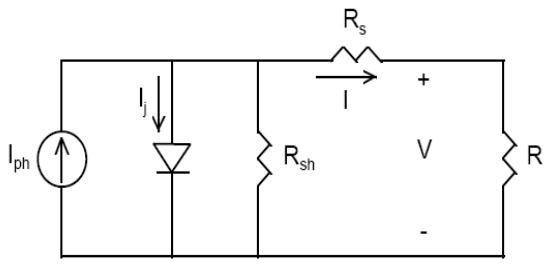

Figure (2): Equivalent circuit for a solar cell

$$
I=I_{p h}-I_{\Xi a}\left(e^{\frac{q V}{k T}}-1\right)
$$

Where $k$ is the Boltzmann constant, $T$ is the absolute temperature, $q$ is the electron charge, $V$ is the cell voltage terminals, Isa is the diode saturation current, Iph is the photo generated current.

The photo generated current is closely related to the solar cell photon flux incident on the cell and its dependence on the wavelength of light. The solar cell Characteristics are affected by solar intensity level and temperature.

For a given solar intensity and operating temperature, the output power depends on the value of a load resistance. As the load increases, the operating point moves along the curve forward to the right. So there is only one value of the load makes the solar panel produce its maximum power. 
A DC/DC convertor may be located between the array and the load and used to optimize the power transfer. Any type of the DC/DC converters may be used, depending on the PV system design requirement. The boost convertor is probably the preferred configuration as it can draw current continuously at the input side, minimizing the need for filtering and energy storage on the array side of the convertor [5]. Figure (3) shows a typical boost convertor used with the solar panel for MPPT. An control algorithm is required to change the duty cycle of the power convertor and thereby, the load line slope will change; in other words, the operating point of the solar panel will be moved toward the MPP.

Solar Panel

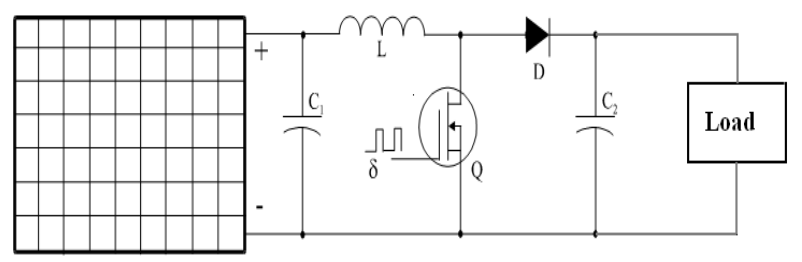

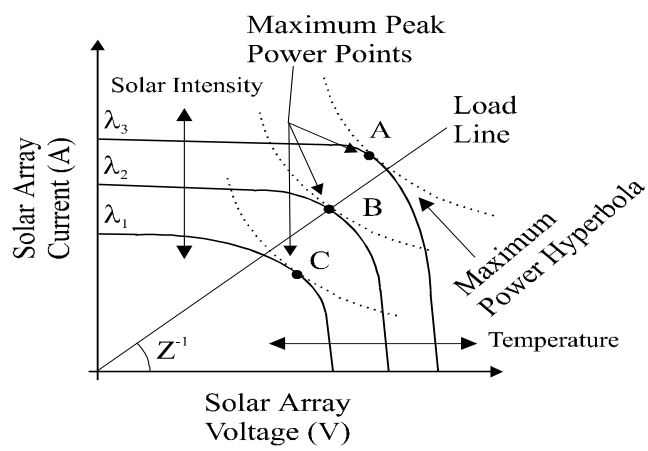

Figure (3): Strategy of MPPT by using boost convertor as a matching circuit in a PV system

\subsection{The proposed PV System Design}

The fuzzy logic algorithm is based on the following rule: " If the last change in the dutycycle (DC) has caused the power to raise, keep moving the duty-cycle (DC) in the same direction; otherwise, if it has caused the power to drop, move it in the opposite direction" [6].

In order to model a system linguistically, the input and output variables of the process to be controlled need to be identified, the subsets that cover the universe of discourse of each variable are to be defined and a linguistic label to each one is to be assigned, then a rule-base by assigning relationships between inputs and outputs is formed. Finally a defuzzification method to be used to generate a crisp output from the fuzzy outputs generated from the rulebase is to be determined.

Figure (4) shows a block diagram for an FLC to be modeled. There are two input linguistic variables. one for the change in power $(\Delta \mathrm{P})$ and the other for a previous change in the dutycycle $(\triangle D C)$. The output linguistic variable is the next change in the duty-cycle $\left(\Delta D_{0}\right)$. The Input and output variables of FLC are related by the following equations:

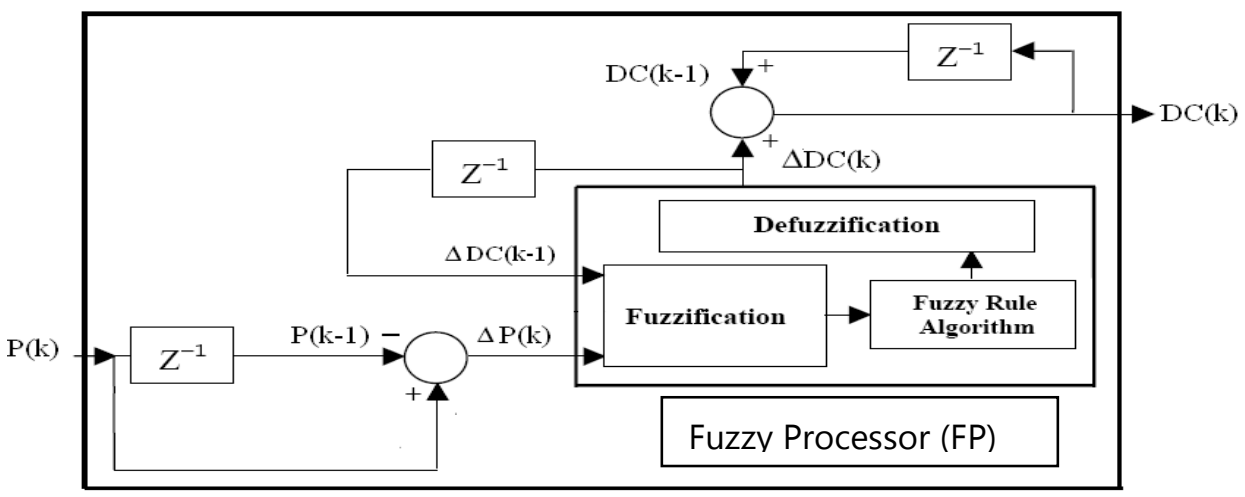

Figure (4): A fuzzy logic controller block diagram 


$$
\begin{aligned}
& \Delta P(k)=P(k)-P(k-1) \\
& \triangle D C_{o}(k)=D C(k)-D C(k-1) \\
& \triangle D C(k)=\Delta D C_{o}(k-1)
\end{aligned}
$$

The fuzzy processor (FP) includes three functional blocks: fuzzification, fuzzy rule algorithm, and defuzzification

2.2 Simulation Study The overall system has been simulated using Matlab/Simulink programme, three values of inductor were used to check the boost operation and boundary condition as shown in Figure (5).

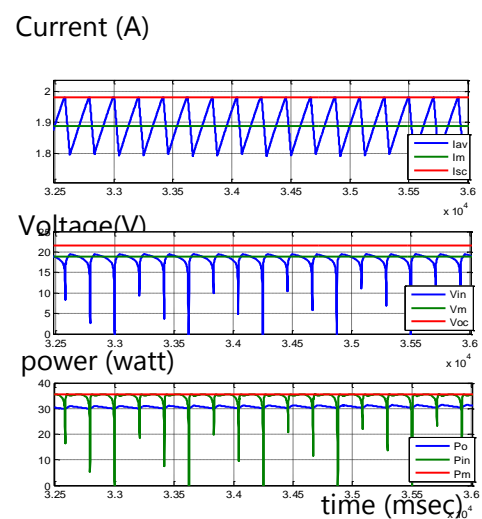

(a)

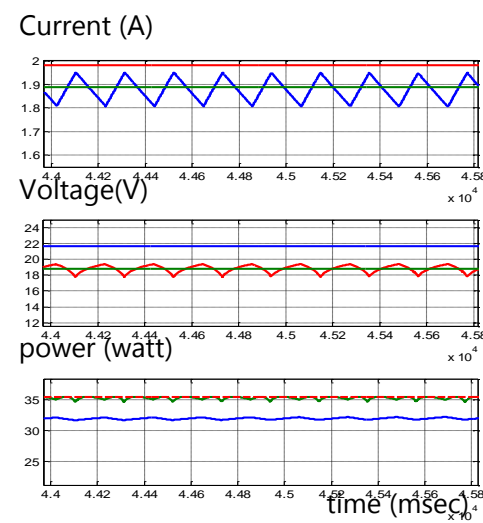

(b)

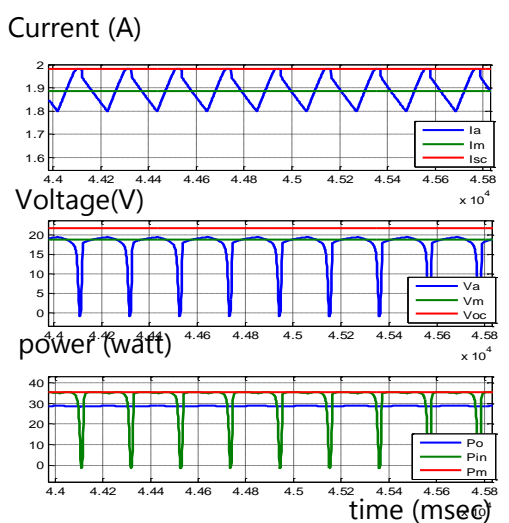

(c)

Figure (5): Boost operation a: in boundary condition $(\mathrm{L}=1.5 \mathrm{mH})$

b: Normal operation $(\mathrm{L}=2 \mathrm{mH})$ c: using under critical value of inductor $(\mathrm{L}=1 \mathrm{mH})$

The output ripple voltage of the boost circuit has been verified for the minimum value of the capacitor $(20 \mathrm{uF})$ to give $1 \%$ of ripple for output voltage as shown in Figure (6).

\subsection{MPPT Simulation Results}

Three fuzzy logic controllers were tested to study the effect of increasing the number of rules by adding more terms of linguistic variables for the system variables, Figure (7) shows the overall simulated system and the three membership FLC.

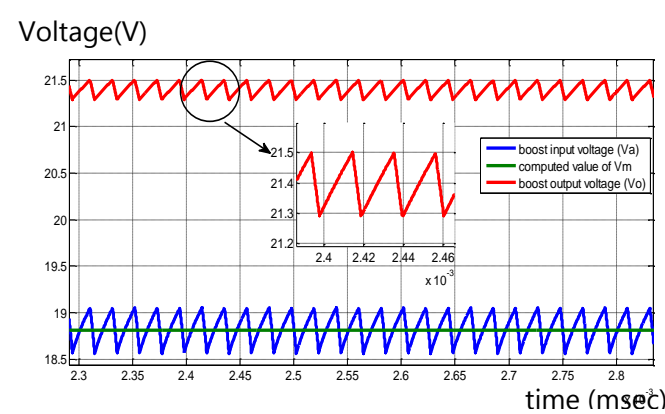

Figure (6): Boost convertor input/output voltage waveform

The system was tested with MPPT under a five level sudden change of sun light intensity as shown in Figure (8). For three memberships FLC for each variable, the tracked power stabilized around this level: $30,15,27,22,32.5$ watt while the maximum output powers under similar conditions were: $33,17.5,30.5,24,36.5$ wats shown in figure ( 8 a). It is clear from the simulation results that the tracker stabilized under MPP, and the tracker efficiency did not exceed $90 \%$ with some fluctuation. An increasing in tracker efficiency is obtained with a five membership FLC tracker as shown in Figure $(8 \mathrm{~b})$, the tracked powers for the same order are: 32, 17, 28, 22.5, 35 watt, the tracker efficiency is improved and reached $97 \%$. For better performance, a seven membership FLC MPPT is designed to give tracking efficiency up to $99.9 \%$ with minimum fluctuation at MPP as shown in Figure $(8 \mathrm{c})$. 

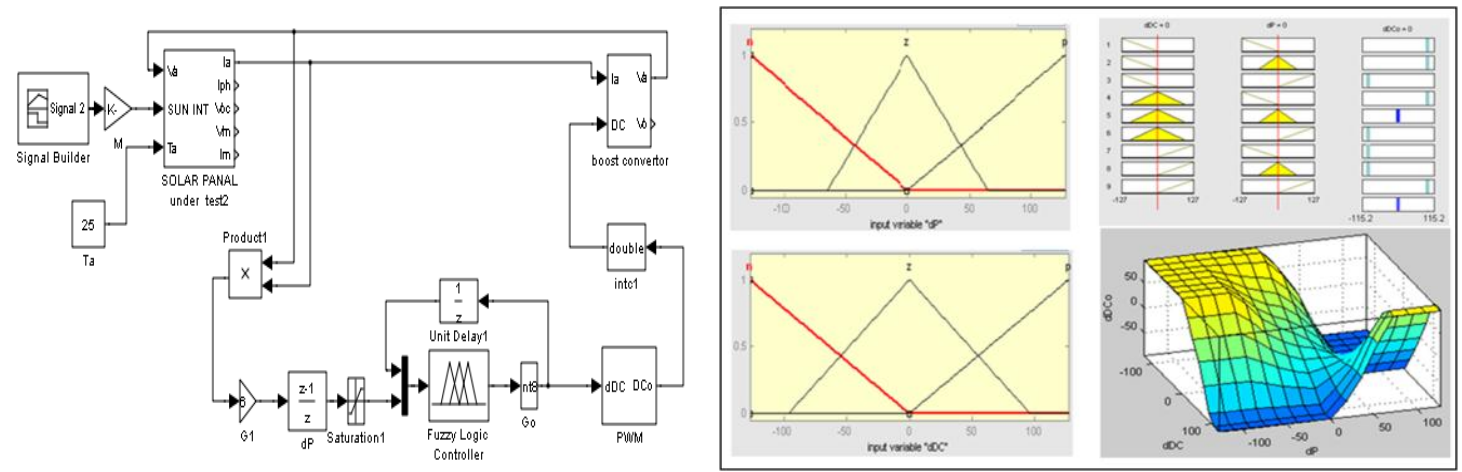

Figure (7): The overall simulated PV system and the Thee terms of linguistic variable FI.C.

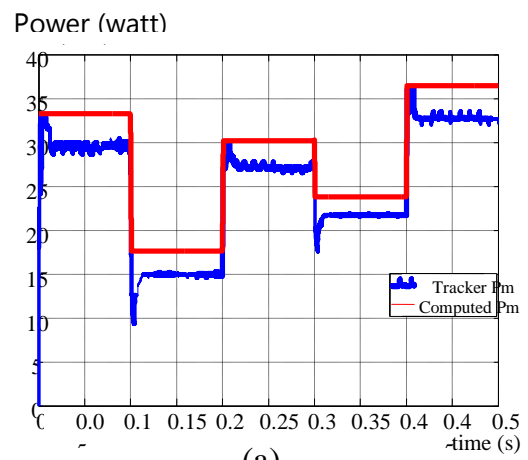

(a)

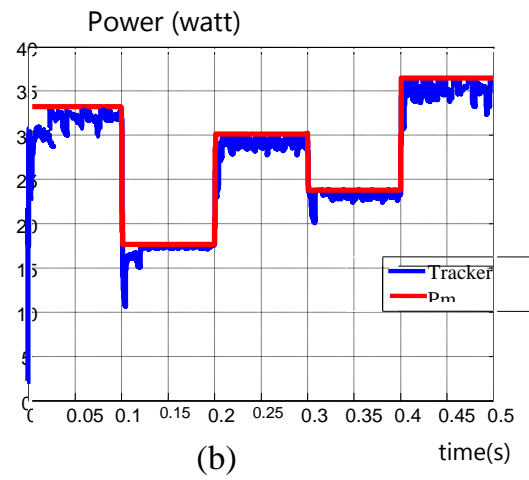

(b)

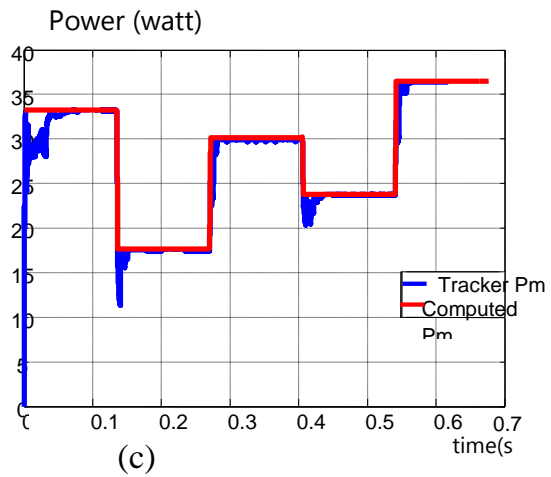

(c)

Figure (8): Solar array output power under the effect of a sudden change in solar intensity level (a) three term FLC MPPT (b) five term FLC MPPT

(c) seven term FLC MPPT

Figure (9) illustrates the MPP tracking process under different levels of solar insolation. Figure ( 9 a) shows the output power versus time and demonstrating that a maximum power point can be sustained with small fluctuation, the peak power that can be delivered from the solar panel under these level of insulation is obtained from the tracing of the output power versus terminal voltage of the solar panel as shown in Figure $(9 \mathrm{~b})$,

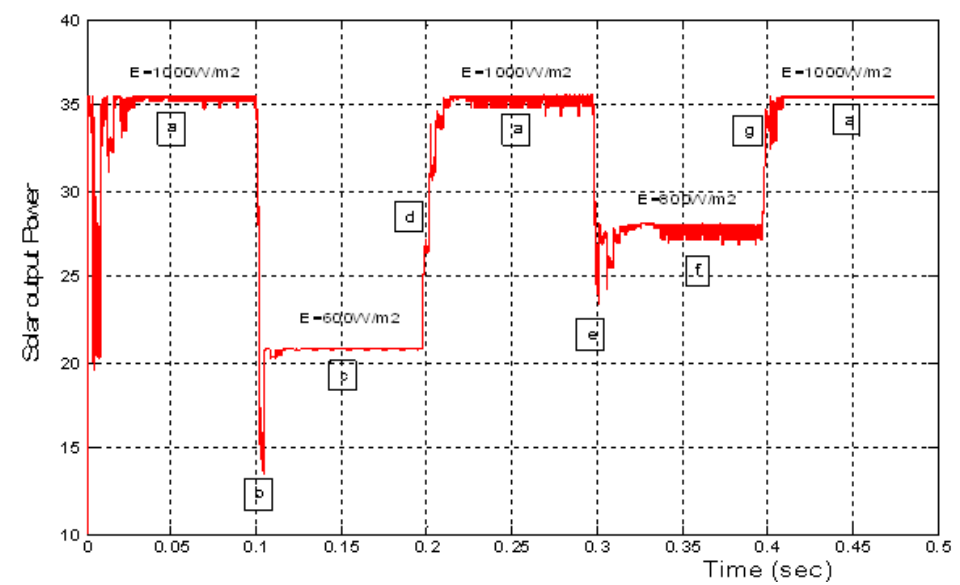

(a)

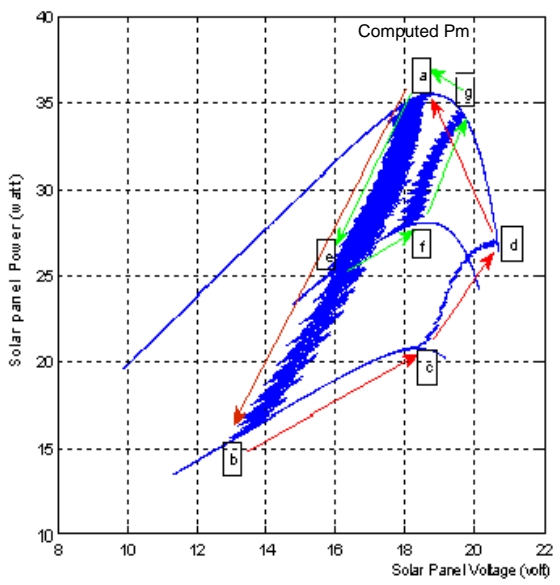

(b)

Figure (9): solar array output power with MPPT under the effect of a sudden change in solar intensity level (E) (a) with time (b) with solar array voltage 


\subsection{Experimental study:}

The overall system has been implemented as shown in the block diagram of Figure (10) The solar panel used in experimental study has the following characteristics under Standard Test Conditions (STC) $\left(25^{\circ} \mathrm{C}\right.$ cell temperature and $1000 \mathrm{~W} / \mathrm{m}^{2}$ irradiation):

Product type: TSM-50(734x651x40mm)

Maximum Power Pm: 34W

Open circuit voltage: $21.7 \mathrm{~V}$

Short circuit current: $2.1 \mathrm{~A}$

Maximum power voltage: $17.5 \mathrm{~V}$

Maximum power current: $1.95 \mathrm{~A}$

The boost convertor parameters were set up in accordance with those used in simulation study where $\mathrm{L}=2 \mathrm{mH}, \mathrm{C}=20 \mathrm{uF}$, the IRF 640 is used as a swiching element $(\mathrm{SW})$ avariable resistive load is used to study the effect of adifferent load, the MC9S12DP256B MCU is used as a digital controller.

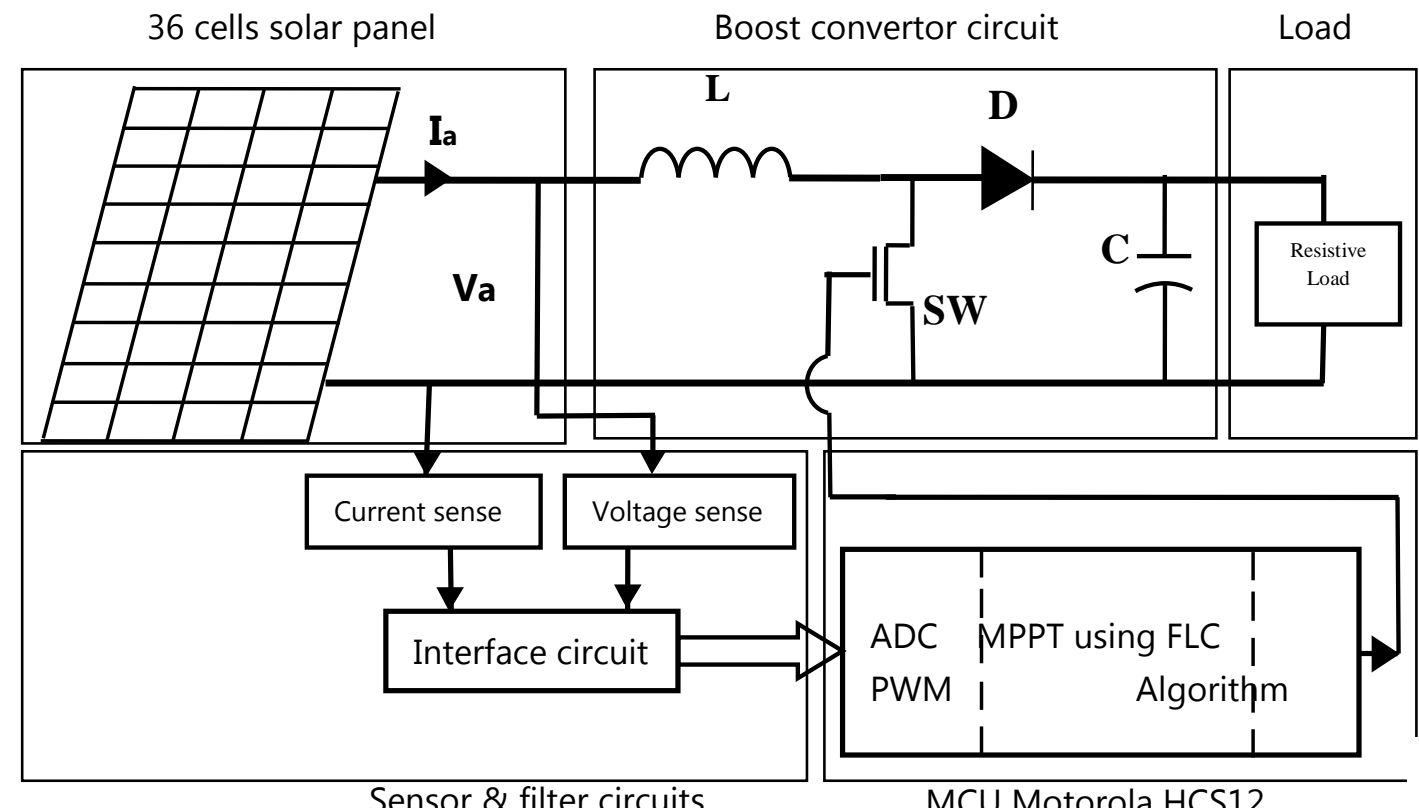

Figure (10): Block diagram of the proposed PV system

\subsection{Digital Controller:}

The use of a microcontroller provides more benefits as the MPPT operation can be enhanced by implementing a digital control strategy. The MC9S12DP256B MCU is shown in Figure (11), the 16-bit device composed of standard on-chip peripherals including a 16-bit central processing unit (Motorola 68HCS12 Microcontroller) [7], 256K bytes of Flash EEPROM, 12K bytes of RAM, $4 \mathrm{~K}$ bytes of EEPROM. Two 8-channel 10-bit ADC, an 8-channel PWM, 29 discrete digital I/O channels (Port A, Port B, Port K and Port E), (Key specifications and technical data are available at website of company).

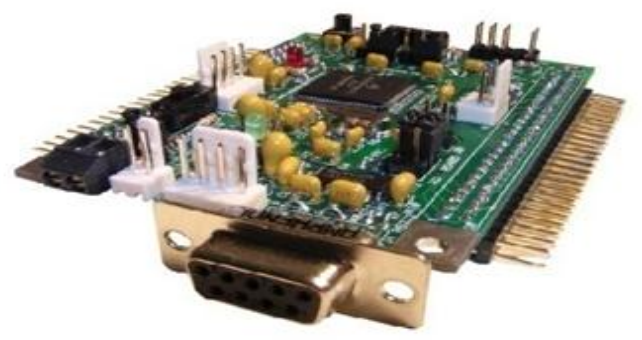

Figure (11): Motorola 68HC12 Microcontroller 
This MCU module has been used to implement FLC based MPPT, in addition the microcontroller will perform the following tasks:

1- Sampling the voltage and current signal at a rate that agree with the system response.

2- Converting the analogue signals that had been sampled in a digital form using the builtin A/D subsystem.

3- Controlling task by computing the next duty-cycle through the FLC MPPT algorithm.

4- Outputting the PWM signal to the boost convertor using the built-in PWM subsystem.

To perform these tasks, the microcontroller will execute an algorithm written in assembly language, the use of assembly language has better performance than high level language in real time application since it is fast to execute and it takes a lower size in byte.

\subsection{MPPT algorithm:}

Figure (12) shows A flow chart for the MPPT control algorithm The MPPT algorithm was written in assembly language and downloaded into the flash memory of the microcontroller using the Debug Monitor (D-Bug12) Supports on-chip with the MC9S12DP256 microcontroller and the HyperTerminal as terminal emulation program supplied with Windows NT.

\subsection{MPPT Practical Results:}

The validation of the MPPT circuit operation and the fuzzy controller activity has been achieved in two steps: first, the MPPT is verified under the effect of using different numbers of fuzzy subsets. Figures (13) and (14) and show the output power of the solar panel by using MPPT FLC with three, five and seven terms of the linguistic variable respectively, a high efficiency tracking with minimum fluctuation was achieved by using seven terms FLC and this was the same as seen in the simulation study before.

The next validation of the MPPT circuit operation determines the fuzzy controller activity under different irradiance suddenly changing condition as shown in Figure (15). Figure (15 a) shows the

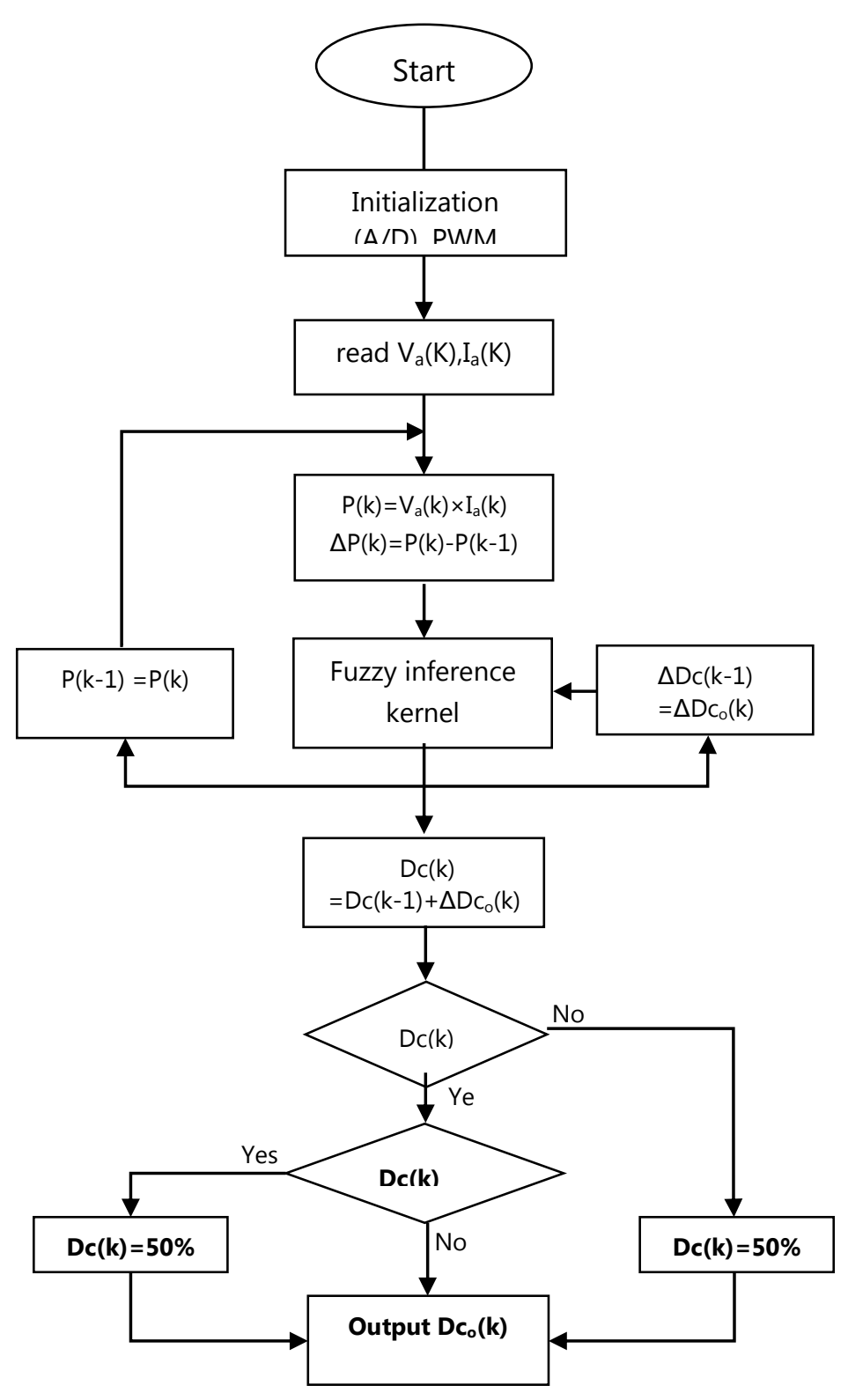

Figure(12): A flow chart for the MPPT control algorithm 
power versus time while Figure (15 b) shows the power trace with voltage of the solar panel, the tracker seems to be very stable by using seven terms of the linguistic variable FLC.

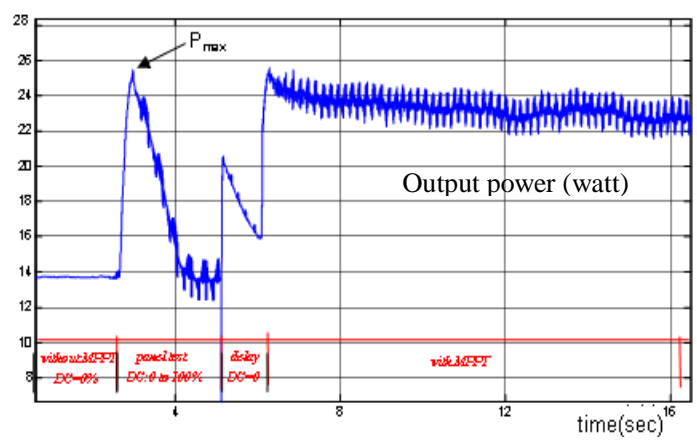

Figure (13): Output power of the solar panel using three terms of linguistic

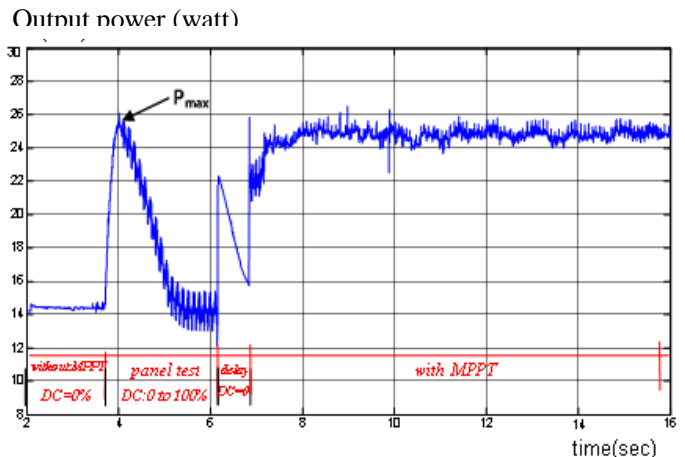

Outbut power (watt)

Power (watt)

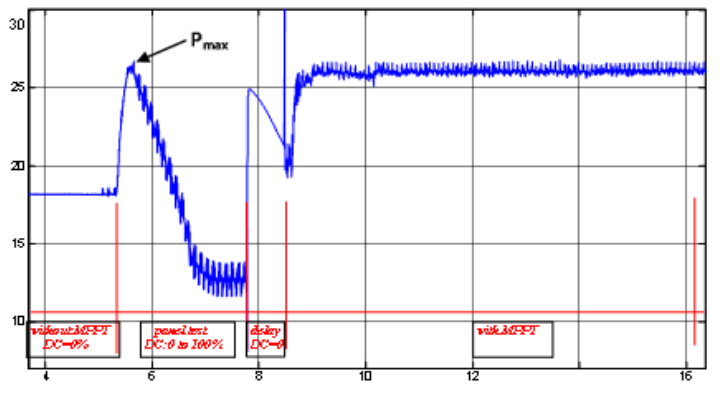

Figure (14): Solar panel output power MPPT using: (a) five terms FLC (b) seven terms FLC

Output power (watt)

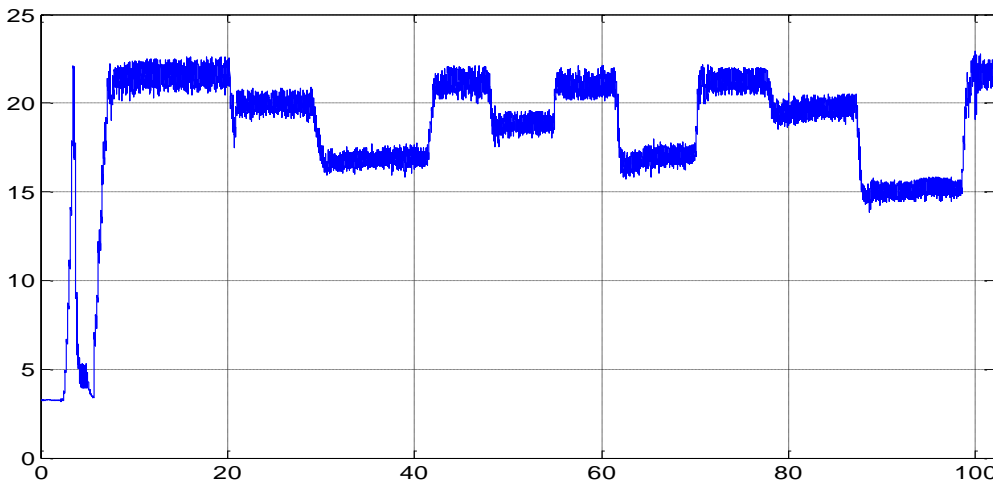

(a)

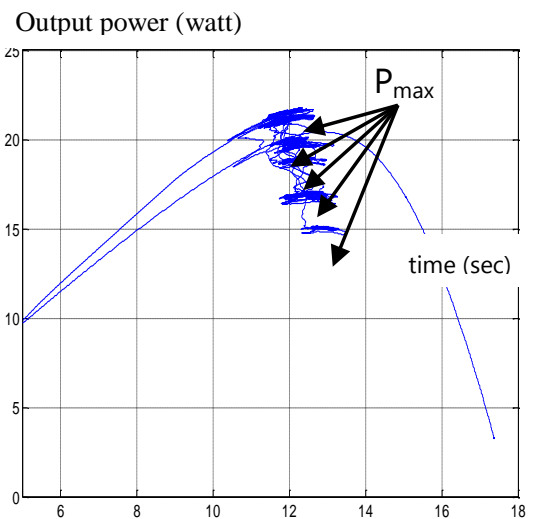

(b)

Figure (15): Solar array output power with MPPT under different sudden change in solar intensity level (a) power versus time (b) power versus panel voltage

The tracker is also tested under the effect of load-change conditions. Figure (16) shows the output power of the solar panel for different load values with and without MPPT. The pressure is increased in steps. It has been seen that, the tracker succeeded in finding the MPP, when the load impedance value is larger than the value of the solar array impedance and failed for load impedance value lower than the value of the inner solar array impedance. This is clearly due to the boost characteristic since the input impedance of the convertor is step-down as the duty-cycle goes-up from 0\% to 100\%. A buck-boost convertor can be used to overcome this problem. 
Output power (watt)

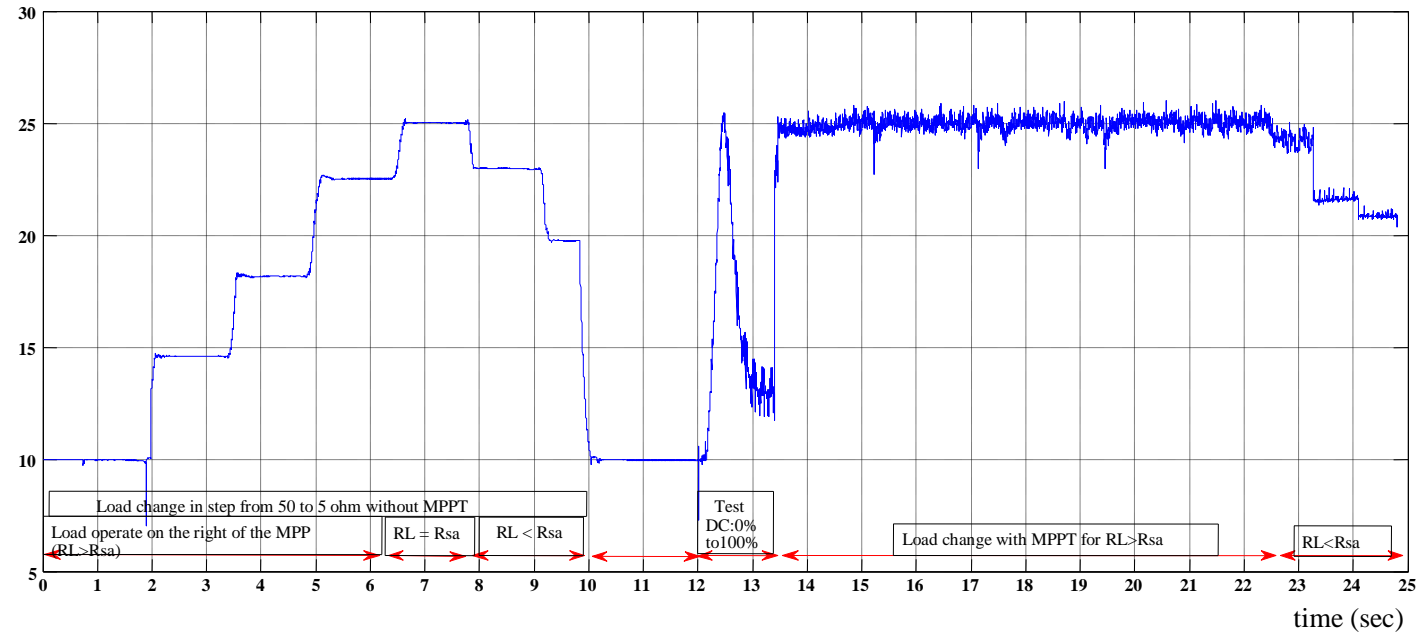

Figure (16): The output power of the solar panel for different load values with and without MPPT

In addition, the tracker has been tested with two type of storage batteries system: 12 volt and 24volt storage cell batteries, Figure (17 a) shows that the charging current (Ic) is increased approximately by $15 \%$ for the 12 volts battery system. For the 24 volt battery system, the current charge for such system is equal to zero without MPPT, and it tends to increase to a value of about 1.2 ampere, when using the MPPT, as shown in Figure (17 b), which can be regarded as a great benefit of using MPPT for different types of storage battery systems; i.e. the tracker can be used with a storage cell battery having a voltage value greater than the solar panel output voltage.
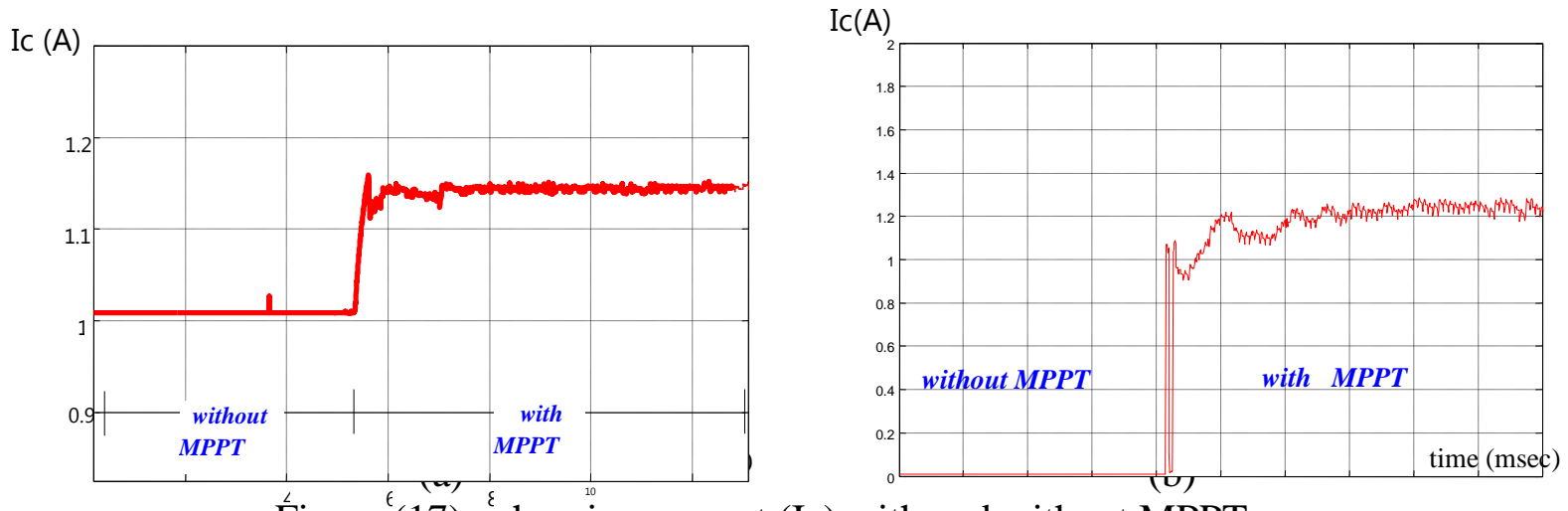

Figure $^{\epsilon}(17)$ : ${ }^{\varepsilon}$ charging current (Ic) with and without MPPT a:for $12 \mathrm{v}$ battery b:for $24 \mathrm{v}$ battery

\section{Conclusions:}

High performance and robustness control can be obtained through Fuzzy control for MPPT of PV array and it is possible to get the capacity of high-adaptive control under a sudden change in solar intensity and temperature of PV array. The proposed MPPT control method consists of fuzzy algorithm and a boost DC/DC power convertor. The control algorithm is applied to track the MPP of the non-linear characteristic of PV array by controlling the duty-cycle of the boost convertor. The tracker efficiency reached up to $99.9 \%$ under different sudden change irradiance level and the system is found to have good stability at MPP. The validity of the proposed fuzzy logic control algorithm is demonstrated in this research through: 
1- Simulation study: the overall system has been simulated using Matlab/Simulink programme, the Simulation study is very significant in FLC design for determining membership selection since this selection is based on trial and error.

2- Practical implementation: the Motorola $\mathrm{HC} 12 \mathrm{MCU}$ has been used to implement the MPPT control algorithm using the fuzzy logic instruction set supported with HC12 MCU. Efficient hardware implementation was achieved by using the on-chip peripherals ( the analog to digital convertor and PWM module).

3- Comparing the proposed MPPT with those given in the literature review the system is found to have good stability at the maximum power point (tracking efficiency up to 99.9\%) with fast convergence and robust performance in all operating conditions and it is ready to be fitted in a larger PV systems installation.

\section{References:}

[1] C.Hua and C.Shen.,"Comparative Study of Peak Power Tracking Techniques for Solar Storage System", IEEE Transactions on Power Electronic System,1998.

[2] M. Veerachary, T. Seniyu., "Voltage-Based Maximum Power Point Tracking Control of PV Systems", IEEE Transactions on Aerospace and Electronic Systems, Vol.38, No.1, pp.262-270, 2002.

[3] T. L. Kottas, Y. S. Boutalis and A.D. Karlis, "New Maximum Power Point Tracker for PV Arrays Using Fuzzy Controller in Close Cooperation With Fuzzy Cognitive Networks", IEEE Transactions on Energy Conversion, Vol. 21, No. 3, September 2006.

[4] Xin Wang and Aiguo Patrick $\mathrm{Hu}$ "An Improved Maximum Power Point Tracking Algorithm For Photovoltaic Systems", Australasian Universities Power Engineering Conference, Brisbane, Australia, 2004.

[5] N. Khachintung, K. Pramotung "RISC-Microcontroller Built-in Fuzzy Logic Controller of Maximum Power Point Tracking for Solar -Powered Light-Flasher Applications", the $30^{\text {th }}$ Annual Conference of the IEEE industrial Electronics Society, Busan, Korea pp. 2673-2678, 2004.

[6] Abou El-Maaty Metwally "Modelling and Simulation of a Photovoltaic Fuel Cell Hybrid System", ph.D. Dissertation, Electrical Engineering University of Kassel, Kassel, Germany , 2005. Ph.D.

[7] HCS12 V1.5 Core User Guide Version 1.2, Motorola, Inc., 2002.

http://www.motorola.com/semiconductors

[8] M.Godoy, N.Franceschetti and M.Friedhofer.,"A Fuzzy Logic Based Photovoltaic Peak Power Tracking Controller”, IEEE, pp.300-305, 1998.

[9] Yordan Chervenkov, Ovid Farhi "Fuzzy Control System with Implementation on an Embedded Microcontroller", This work was supported in part by the Technical University of Varna, Varna City, Bulgaria, Europe, October 18, 2005.

[10] M68HC12 and HCS12 Microcontrollers "CPU12 Reference Manual” , Motorola, Inc., 2002. http://www.motorola.com/semiconductors 